\title{
THE MeTHOd For OPTIMUM Design OF RESIN Injection Molding Process Conditions Using MUlTIVARIATE ANALYSIS WITH ROBUST Parameter Design
}

\author{
Eiji Toma \\ Department of Mechanical Engineering, National Institute of Technology, Tomakomai \\ College, Hokkaido, Japan
}

\begin{abstract}
In recent years, the demand for plastic products has increased, and along with the deepening of academics, mass production, weight reduction, and high precision are progressing. In the fields of design development and production technology, there are many issues related to quality assurance such as molding defects and product strength. In particular, in the resin molding process, there is a high degree of freedom in product shape and mold structure, and it is an important issue to create quality functions that apply analysis of complex multidimensional information. In this study, the important factors of the resin molding process related to the optimization of resin strength are extracted by applying the multivariate analysis method and robust parameter design. As a result of verification of the proposed method, it is clarified that uniformization of the resin filling density in the mold is extremely important for stabilizing the resin strength.
\end{abstract}

\section{KEYWORDS}

Resin molding process, Multivariate analysis, Robust parameter design, Energetic SN ratio, Resin filling characteristics

\section{INTRODUCTION}

In recent years, in order to contribute to environmental conservation and the construction of a sustainable society, the automobile industry is developing eco-cars such as hybrid vehicles and EVs (electric vehicles). At the same time, there is a great need for vehicle body weight reduction technology to improve fuel efficiency. On the other hand, it is necessary to improve market competitiveness at the same time, so the realization of weight reduction and cost reduction is an issue. As a trump card for weight reduction, resin materials are being developed for application to various parts. The density of iron is about $7.8 \mathrm{~g} / \mathrm{cm}^{3}$, while that of polypropylene (PP) which is a typical resin material is about 0.9 to $1.2 \mathrm{~g} / \mathrm{cm}^{3}$. The density is quite low, and expectations for weight reduction by material replacement are increasing [1].

The following is an example of weight reduction using a resin material. As an example, resinification of steel pulleys for automobiles is being actively carried out. A pulley is a mechanical element component used for transmitting the rotation of an engine to a belt, positioning the belt and adjusting tension. The resin pulley is insert-molded with a metal bearing, and most of the materials are thermosetting resins such as phenol resin that improve heat resistance and oil resistance. 
Mechanical Engineering: An International Journal (MEIJ) Vol. 08, No. 1/2/3/4, November 2021

As shown in Figure 1, especially European automobile manufacturers are promoting the use of resin for power steering pulleys and idler pulleys. The resinification rate of the transmission pulley used for the drive transmission parts around the engine has reached about 30\%. However, for automobile manufacturers in Japan, the resinification rate of pulleys is as low as 5 to $6 \%$, which is an important issue in promoting technology for reducing the weight of materials. Resinification is the replacement of steel parts with resin, and the purpose is to reduce weight and cost. The resin pulleys currently in practical use cannot be said to have sufficient characteristics as a substitute for steel pulleys in terms of strength and dimensional stability [2].

Section 2 of this paper outlines the injection molding process. In Section 3, we apply multivariate analysis to extract key elements of the resin molding process related to resin strength optimization. Section 4 focuses on the control function of the resin filling density in the mold (input / output relationship of molten energy related to the resin flow) from the analysis results of Section 3. Based on the original strength of materials mechanics, we propose a robust parameter design with the ideal function of stabilizing the resin filling density. [3-7].

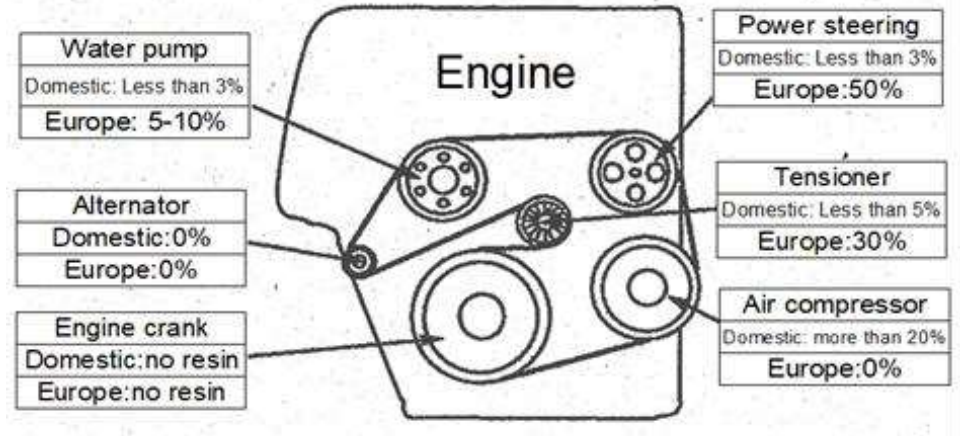

Figure 1. Resin status of automobile pulleys.

\section{Outline of Resin Injection Molding Process}

There are several types of resin molding methods depending on the purpose, but in this research, we approach the optimization of the injection molding process suitable for the mass production method of resin pulleys. The injection molding method is a method of obtaining a molded product by injecting a heated and melted material into a mold and cooling and solidifying the material. It is suitable for mass production of products with complicated shapes and is a major field of molding processing. As shown in Figure 2, injection molding is one of the molding methods using a mold. This is a processing method in which a material such as synthetic resin (plastic) is heated, melted, sent to a mold, and then cooled to form a target part. As shown in Figure 3, the injection molding machine is mainly composed of three parts: (1) injection device, (2) mold clamping device, and (3) mold.

Through this process, continuous production becomes possible [8]. The injection molding machine is divided into a mold clamping unit and an injection unit [9]. In practice, it is often the case that a plurality of molded products are manufactured at the same time by a single injection molding, so it is important that the molten material uniformly flows into all parts. Injection molding is a processing technique suitable for mass production. However, in order to produce a highly accurate molded product, it is necessary to extract various processing parameter conditions such as resin material selection accuracy, mold processing accuracy, and temperature and speed at which the material is injected. 


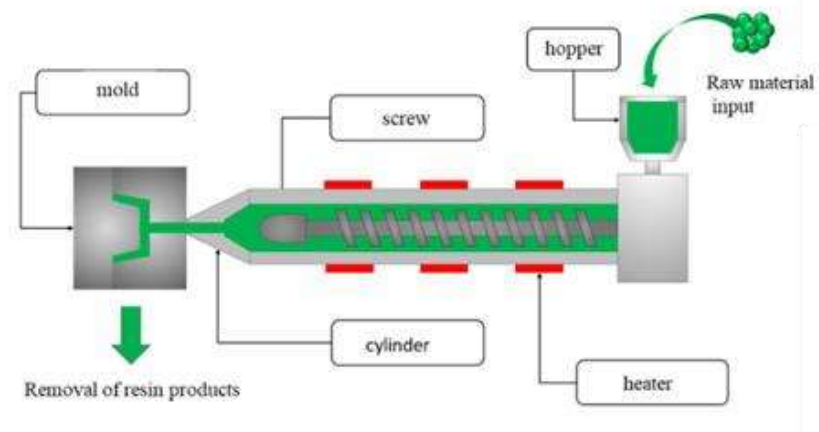

Figure 2. Main structure and model of injection molding.

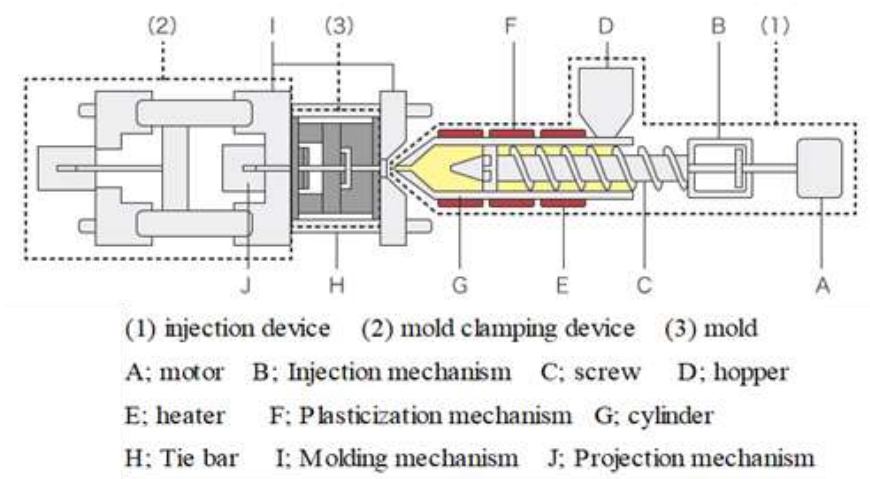

Figure 3. Injection molding machine. The injection molding process is roughly divided into 6 steps: (1) mold clamping, (2) injection, (3) pressure retention, (4) cooling, (5) mold opening,

(6) product removal.

\section{CORRElation Verification Of RESIN Filling DenSity bY MUlTivariate ANALYSIS}

In this study, we apply a multivariate analysis method to the correlation between the resin filling density obtained in the experiment and the estimated it. From the correlation results, we verify the validity of the filling density and the effectiveness of the important factors that affect the resin filling characteristics. In the correlation analysis, the "T method" which is a quality engineering method that can estimate the output value from multivariate data is adopted.

The T method is one of the multivariate analysis methods, and is a mathematical method that estimates one objective variable (output value) from multiple item variables (continuous variables) in the same way as multiple regression analysis. Comprehensive estimation of the correlation is possible from the relationship between each item and the output value. Furthermore, in the effectiveness analysis of important factors that affect the resin filling characteristics, the "MT system (hereinafter referred to as MTS") is adopted. MTS is a general term for a group of multivariate analysis methods that combine quality engineering and theory based on statistical mathematics, and is widely applied in the fields of science and technology such as pattern recognition, prediction / estimation, and inspection. A feature of MTS is that it can evaluate important factors related to prediction and estimation and process multidimensional information [10]. Since MTS includes the MT method based on statistical mathematics and its own feature extraction technology, it is a system that emphasizes practical use rather than simply multivariate data analysis theory. Figure 4 shows an overview of the MTS components [11]. 
(a) Mathematical pattern recognition: MT method, RT method

Both MT / RT methods are methods for pattern recognition. As a common point, the normal group is used as a reference (unit space), and the difference in pattern from that is calculated as the distance. A large distance indicates that it is far from the reference pattern. The difference is that the MT method has the highest pattern recognition accuracy and may be regarded as one of AI (Artificial Intelligence) [12].

(b) Mathematical prediction / estimation: T method, T-MSR

Similar to multiple regression analysis, the $\mathrm{T}$ method is a means for predicting and estimating output values (objective variables) from multivariate data (explanatory variables). It has the advantage that there is no instability or impossibility of calculation when the number of samples is small and the multi-collinearity problem, which is a weak point of multiple regression analysis. T-MSR is a calculation method developed from the T method, and is known to obtain better prediction accuracy than other mathematics in many cases.

(a) Feature value extraction

In pattern recognition for waveforms and images, the success or failure of feature extraction technique determines. MTS includes feature extraction technique called "variation value" and "abundance value" from these patterns [13].

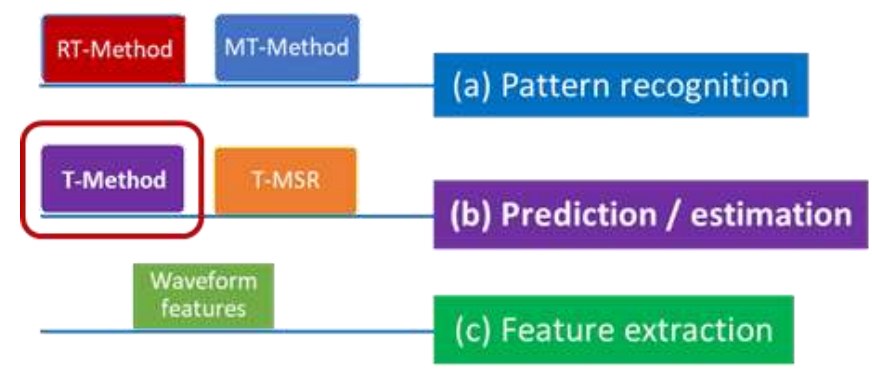

Figure 4. Method components of MTS.

\subsection{Computation Formula for the $T$ Method}

The $\mathrm{T}$ Method defines the Unit Space where the output value is in the medium position and homogeneous (densely populated). The computation procedure of the T Method is explained below [14].

\subsubsection{Definition of the Unit Space and Computation of the Average of Relevant Items and Outputs}

Let's suppose that, as shown in Table 1, $\mathrm{n}$ number of data have been obtained for the Unit Space. All the items of the data must be in same dimension as image density or must be no dimension data. From the $n$ number of samples in the Unit Space, we find average values $\overline{x_{1}}, \overline{x_{2}}, \cdots, \overline{x_{k}}$ and average output value $\bar{y}=M_{0}$ for all items. Accordingly, the average values work out as follows:

$$
\bar{x}_{j}=-\frac{1}{n}\left(x_{1 j}+x_{2 j}+\cdots+x_{n j}\right)(j=1,2, \cdots, k)
$$

$n$ 
Mechanical Engineering: An International Journal (MEIJ) Vol. 08, No. 1/2/3/4, November 2021

$$
\bar{y}=M_{0}=\frac{1}{-}\left(y_{1}+y_{2}+\cdots+y_{n}\right)
$$

Table 1 also shows these average values. One of the average values obtained from the $n$ members of the Unit Space is the center of the Unit Space.

Table 1. Data for the Unit Space and averages values of the items and outputs.

\begin{tabular}{cccccc}
\hline & \multicolumn{5}{c}{ Ite $\mathbf{m} /$ variable } \\
\cline { 2 - 5 } Data No. & $\mathbf{1}$ & $\mathbf{2}$ & $\ldots$ & $\mathrm{k}$ & Output value \\
\hline 1 & $\mathrm{x}_{11}$ & $\mathrm{x}_{12}$ & $\ldots$ & $\mathrm{x}_{1 \mathrm{k}}$ & $\mathrm{y}_{1}$ \\
2 & $\mathrm{x}_{21}$ & $\mathrm{x}_{22}$ & $\ldots$ & $\mathrm{x}_{2 \mathrm{k}}$ & $\mathrm{y}_{2}$ \\
$\ldots$ & $\ldots$ & $\ldots$ & $\ldots$ & $\ldots$ & $\ldots$ \\
$\mathrm{n}$ & $\mathrm{x}_{\mathrm{n} 1}$ & $\mathrm{x}_{\mathrm{n} 2}$ & $\ldots$ & $\mathrm{x}_{\mathrm{nk}}$ & $\mathrm{y}_{\mathrm{n}}$ \\
\hline Average & $\overline{x_{1}}$ & $\overline{x_{2}}$ & & $\overline{x_{k}}$ & $\bar{y}=M_{0}$ \\
\hline
\end{tabular}

\subsubsection{Definition of Signal Data}

All data items marked 1, left unselected for the Unit Space are treated as Signal data. Signal data is shown in Table 2. "Signal data" refers to all data used for finding the proportional coefficient $\beta$ and $\mathrm{SN}$ ratio $\eta$, which will be discussed in Section 3.1.4.

Table 2. Signal data.

\begin{tabular}{cccccc}
\hline & \multicolumn{5}{c}{ Item/variable } \\
\cline { 2 - 5 } Data No. & $\mathbf{1}$ & $\mathbf{2}$ & $\ldots$ & $\mathbf{k}$ & Output value \\
\hline 1 & $\mathrm{x}_{11}^{\prime}$ & $\mathrm{x}_{12}^{\prime}$ & $\ldots$ & $\mathrm{x}_{1 \mathrm{k}}^{\prime}$ & $\mathrm{y}_{1}^{\prime}$ \\
2 & $\mathrm{x}_{21}^{\prime}$ & $\mathrm{x}_{22}^{\prime}$ & $\ldots$ & $\mathrm{x}_{2 \mathrm{k}}^{\prime}$ & $\mathrm{y}_{2}^{\prime}$ \\
$\ldots$ & $\ldots$ & $\ldots$ & $\ldots$ & $\ldots$ & $\ldots$ \\
$l$ & $x_{l 1}{ }^{\prime}$ & $x_{l 2}{ }^{\prime}$ & $\ldots$ & $x_{l k}{ }^{\prime}$ & $y_{l}^{\prime}$ \\
\hline
\end{tabular}

\subsubsection{Normalization of Signal Data}

Signal Data is normalized using the average values of items and the output values of samples in the Unit Space. Normalization is performed by subtracting the average value $\bar{x}_{j}$ of item $j$ in the Unit Space from value $x_{i j}{ }^{\prime}$ of item $j$ of the $i$-th Signal Data.

$$
X_{i j}=x_{i j}{ }^{\prime}-\bar{x}_{j}(i=1,2, \cdots, l ; j=1,2, \cdots, k)
$$

Likewise, normalization is performed by subtracting average value $M_{0}$ of the output from the Unit Space from output value $y_{i}^{\prime}$ of the $i$-th Signal Data.

$$
M_{i}=y_{i}^{\prime}-M_{0}(i=1,2, \cdots, l)
$$

Normalized Signal data is shown in Table 3. 
Mechanical Engineering: An International Journal (MEIJ) Vol. 08, No. 1/2/3/4, November 2021

Table 3. Normalized Signal data.

\begin{tabular}{cccccc}
\hline & \multicolumn{5}{c}{ Item/variable } \\
\cline { 2 - 5 } Data No. & $\mathbf{1}$ & $\mathbf{2}$ & $\ldots$ & $\mathbf{k}$ & Output value \\
\hline 1 & $\mathrm{X}_{11}$ & $\mathrm{X}_{12}$ & $\ldots$ & $\mathrm{X}_{1 \mathrm{k}}$ & $\mathrm{M}_{1}$ \\
2 & $\mathrm{X}_{21}$ & $\mathrm{X}_{22}$ & $\ldots$ & $\mathrm{X}_{2 \mathrm{k}}$ & $\mathrm{M}_{2}$ \\
$\ldots$ & $\ldots$ & $\ldots$ & $\ldots$ & $\ldots$ & $\ldots$ \\
$l$ & $X_{l 1}$ & $X_{l 2}$ & $\ldots$ & $X_{l k}$ & $M_{l}$ \\
\hline
\end{tabular}

\subsubsection{Computation of Proportional Coefficient $\beta$ and SN Ratio $\eta$ (in Duplicate Ratio) for all Items}

We will next compute proportional coefficient $\beta$ and $\mathrm{SN}$ ratio $\eta$ for all items. How the computation is performed is explained with item 1 as an example:

Proportional coefficient;

$$
\beta_{1}=\frac{M_{1} X_{11}+M_{2} X_{21}+\cdots+M_{l} X_{l 1}}{r}
$$

\section{$\mathrm{SN}$ ratio;}

$\eta_{1}=\left\{\begin{array}{c}\frac{\frac{1}{r}\left(s_{\beta 1}-V_{e 1}\right)}{V_{e 1}}\left(\text { when } S_{\beta 1}>V_{e 1}\right) \\ 0 \quad\left(\text { when } S_{\beta 1} \leq V_{e 1}\right)\end{array}\right.$

Where:

Effective divider;

$$
r=M_{1}^{2}+M_{2}^{2}+\cdots+M_{l}^{2}
$$

Total variation;

$$
S_{T 1}=X_{11^{2}}+X_{21^{2}}+\cdots+X_{l 1}^{2}(f=l)
$$

Variation of Proportional term;

$$
S_{\beta 1}=\frac{\left(M_{1} X_{11}+M_{2} X_{21}+\cdots+M_{l} X_{l 1}\right) 2}{r}(f=1)
$$

Error variation;

$S_{e 1}=S_{T 1}-S_{\beta 1}(f=l-1)$

Error variance;

$$
S_{e 1}
$$

$V_{e 1}=$

$$
l-1
$$


Mechanical Engineering: An International Journal (MEIJ) Vol. 08, No. 1/2/3/4, November 2021

From item 2 up to item $k$, we will likewise find proportional coefficient $\beta$ and SN ratio $\eta$. This operation yields the results that are shown in Table 4.

Table 4. Proportional coefficient $\beta$ and $S N$ ratio $\eta$, item by item.

\begin{tabular}{ccccc}
\cline { 2 - 5 } & \multicolumn{4}{c}{ Item/variable } \\
\cline { 2 - 5 } $\boldsymbol{n}, \boldsymbol{1}$ & $\mathbf{1}$ & $\ldots$ & $\mathbf{k}$ \\
\hline Proportional $\beta$ & $\beta_{1}$ & $\beta_{2}$ & $\ldots$ & $\beta_{\mathrm{k}}$ \\
SN ratio $\eta$ & $\eta_{1}$ & $\eta_{2}$ & $\ldots$ & $\eta_{\mathrm{k}}$ \\
\hline
\end{tabular}

\subsubsection{Computation, Signal by Signal, of Integrated Estimate Value $M^{\wedge}$ of Output}

An item-by-item estimated value is found for each piece of Signal Data using the proportional coefficient $\beta$ and SN ratio $\eta$, item by item. The estimated value of the output of item 1 for the $i$-th Signal Data is:

$$
\widehat{M}_{i 1}=\frac{X_{i 1}}{\beta_{1}}
$$

An estimation is likewise made of item 2 through item $l$ for the $i$-th Signal Data. And finally an integration of the result is performed by weighting it with $\eta_{1}, \eta_{2}, \cdots, \eta_{k}$, which is the estimated measure of precision of each item. Thus, the integrated estimate value $M_{i}$ of the output of the $i$-th Signal Data becomes:

$$
\widehat{M}_{i}=\frac{\eta_{1} \times \frac{X_{i 1}}{\beta_{1}}+\eta_{2} \times \frac{X_{i 2}}{\beta_{2}}+\cdots+\eta_{k} \times \frac{X_{i k}}{\beta_{k}}}{\eta_{1}+\eta_{2}+\cdots+\eta_{k}} \quad(i=1,2, \cdots, l)
$$

Table 5 shows the real values (measured values) of the Signal Data $M_{1}, M_{2}, \cdots, M_{l}$ and the integrated estimate Values $M_{1}, M_{2}, \cdots, M_{l}$.

Table 5. Measured values and integrated estimate values of signal data.

\begin{tabular}{ccc}
\hline Data No. & $\begin{array}{c}\text { Measured } \\
\text { value }\end{array}$ & $\begin{array}{c}\text { Integrated } \\
\text { estimate value }\end{array}$ \\
\hline 1 & $M_{1}$ & $\bar{M}_{1}$ \\
2 & $M_{2}$ & $M_{2}$ \\
$:$ & $:$ & $:$ \\
$:$ & $:$ & $:$ \\
$l$ & $M_{l}$ & $M_{l}$ \\
\hline
\end{tabular}

\subsubsection{Computation of Integrated Estimate SN Ratio}

The Integrated Estimate SN Ratio is computed using the following equation based on Table 5. Integrated Estimate SN Ratio; 


$$
\eta=10 \log \left[\frac{\frac{1}{r}\left(S_{\beta}-V_{e}\right)}{V_{e}}\right](d b)
$$

Where:

Linear equation;

$$
L=M_{1} \bar{M}_{1}+M_{2} \bar{M}_{2}+\cdots+M_{l} M_{l}
$$

Effective divider;

$$
r=M_{1}^{2}+M_{2}^{2}+\cdots+M_{1}^{2}
$$

Total variation;

$$
S_{T}=M_{1}^{2}+M_{2}^{2}+\cdots+M_{l}^{2}(f=l)
$$

Variation of proportional term;

$$
S_{\beta}=\frac{L^{2}}{r}(f=1)
$$

\section{Error variation;}

$$
S_{e}=S_{T}-S_{\beta}(f=l-1)
$$

Error variance;

$$
V_{e 1}=\frac{S_{e}}{l-1}
$$

\subsection{Computation Formula for the MT Method}

This section describes the computation formula for the MT method. In the MT method, a reference data group is configured as a unit space (reference data), and the degree of deviation from the unit space is calculated by an evaluation index called Mahalanobis Distance (hereinafter referred to as MD). This is a method for discriminant analysis of whether or not the target data (also called unknown data) belongs to the unit space (normal / abnormal). MD was invented by Indian statistician Dr. Mahalanobis. This is the result of converting multivariate information, in which multiple variables are intricately intertwined, into a single piece of information called distance. MD is a multidimensional distance that also considers correlation, and can be said to be a type of distance computational method. As shown in Figure 5, if the MD is small, it can be determined that the pattern is short distance to the unit space (normal), and if the MD is large, it can be determined that the pattern is long distance from the unit space (abnormal).

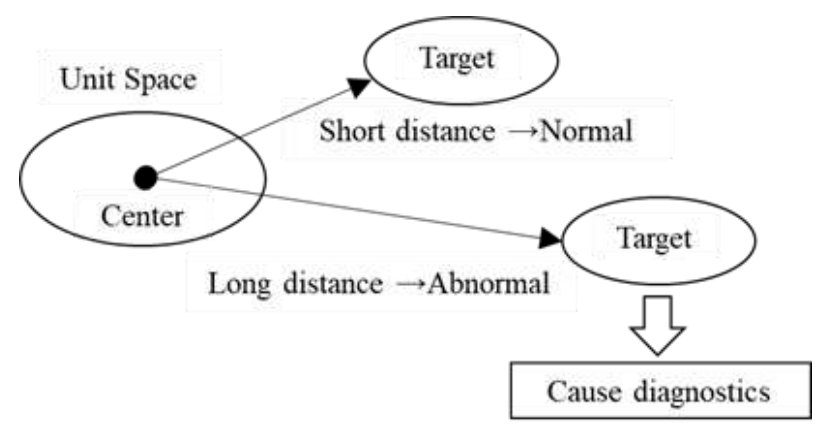

Figure 5. Conceptual drawing of the MT method. 


\subsubsection{Unit Data and Normalization}

In the MT method, variables with different units are mixed, so it is necessary to normalize the data. Let us suppose that, as Unit Data, $k$ variables and $n$ samples have been acquired, as given in Table 6. The Table also shows the average value and standard deviation of each variable. We will compute the normalized value $X$ for each variable as follows:

$$
X_{i j}=\frac{x_{i j^{\prime}}-\bar{x}_{j}}{\sigma_{j}}(i=1,2, \cdots, n ; j=1,2, \cdots, k)
$$

The normalized data is repeated in Table 7 . The average value of each variable after normalization is 0 , and its standard deviation is 1 . Note that the standard deviation $\sigma$ in the MT method is found by the following computation formula in which all of the data form the population. Through this step, the average value of the MD of the Unit Data will be 1 (one).

Generally, in the computation of standard deviation, the symbol " $\sigma$ " is used as the symbol of the population standard deviation, but in this paper, it is intentionally used as the symbol of the standard deviation obtained from the data.

$$
\sigma=\sqrt{\frac{\sum\left(x_{i}-\bar{x}\right)^{2}}{n}}
$$

Table 6. Unit data.

\begin{tabular}{ccccc}
\hline & \multicolumn{4}{c}{ Variable } \\
\cline { 2 - 5 } Sample No. & $\mathbf{1}$ & $\mathbf{2}$ & $\ldots$ & $\mathbf{k}$ \\
\hline 1 & $\mathrm{x}_{11}$ & $\mathrm{x}_{12}$ & $\ldots$ & $\mathrm{x}_{1 \mathrm{k}}$ \\
2 & $\mathrm{x}_{21}$ & $\mathrm{x}_{22}$ & $\ldots$ & $\mathrm{x}_{2 \mathrm{k}}$ \\
$\ldots$ & $\ldots$ & $\ldots$ & $\ldots$ & $\ldots$ \\
$\mathbf{N}$ & $\mathrm{x}_{\mathrm{n} 1}$ & $\mathrm{x}_{\mathrm{n} 2}$ & $\ldots$ & $\mathrm{x}_{\mathrm{nk}}$ \\
\hline Average & $\overline{x_{1}}$ & $\overline{x_{2}}$ & $\ldots$ & $\overline{x_{k}}$ \\
\hline Standard & $\sigma_{1}$ & $\sigma_{2}$ & $\ldots$ & $\sigma_{\mathrm{k}}$ \\
deviation & & & & \\
\hline
\end{tabular}

Table 7. Normalized data.

\begin{tabular}{ccccc}
\hline & \multicolumn{4}{c}{ Variable } \\
\cline { 2 - 5 } Sample No. & $\mathbf{1}$ & $\mathbf{2}$ & $\ldots$ & $\mathbf{k}$ \\
\hline 1 & $\mathrm{X}_{11}$ & $\mathrm{X}_{12}$ & $\ldots$ & $\mathrm{X}_{1 \mathrm{k}}$ \\
2 & $\mathrm{X}_{21}$ & $\mathrm{X}_{22}$ & $\ldots$ & $\mathrm{X}_{2 \mathrm{k}}$ \\
$\ldots$ & $\ldots$ & $\ldots$ & $\ldots$ & $\ldots$ \\
$\mathrm{n}$ & $\mathrm{Xn}_{1}$ & $\mathrm{Xn}_{2}$ & $\ldots$ & $\mathrm{Xn}_{\mathrm{k}}$ \\
\hline Average & 0 & 0 & $\ldots$ & 0 \\
\hline Standard & 1 & 1 & $\ldots$ & 1 \\
deviation & & & & \\
\hline
\end{tabular}




\subsubsection{Computations of Correlation Matrices and Inverse Matrices}

As concerns the $k$ varieties of variables in Table 7, we will calculate the correlation matrix $\boldsymbol{R}$. A correlation matrix is a $k \times k$ square matrix.

$$
\boldsymbol{R}=\left[\begin{array}{ccc}
1 & \cdots & r_{1 k} \\
\vdots & \ddots & \vdots \\
r_{k 1} & \cdots & 1
\end{array}\right]
$$

Where:

$$
r_{i j}=\frac{\sum\left(X_{p i} \times X_{p j}\right)}{n}(p=1, \cdots, n)
$$

Next, we calculate the inverse matrix $R^{-1}$ of correlation matrix $R$, and call it matrix $A$.

$$
\boldsymbol{A}=\boldsymbol{R}^{-1}=\left[\begin{array}{ccc}
a_{11} & \cdots & a_{1 k} \\
\vdots & \ddots & \vdots \\
a_{k 1} & \cdots & a_{k k}
\end{array}\right]
$$

\subsubsection{Computation}

Target data (unknown data) is represented as follows:

$$
\boldsymbol{y}=\left(y_{1}, y_{2}, \cdots, y_{k}\right)
$$

This data is normalized into $\boldsymbol{Y}$ in accordance with the equation given above (21):

$$
\boldsymbol{Y}=\left(Y_{1}, Y_{2}, \cdots, Y_{k}\right)
$$

Whereupon the MD is found through:

$$
D^{2}=\frac{\boldsymbol{Y A \boldsymbol { Y } ^ { T }}}{k}=\sum_{i=1}^{k} \sum_{j=1}^{k} a_{i j} Y_{i} Y_{j} / k
$$

With the MT Method, note that the MD obtained is given in a squared value, $D^{2}$. Unless otherwise noted, the expression in the form of a squared value will be used throughout the rest of this paper.

\subsection{Measured / Estimated Value Correlation Verification of Resin Filling Density}

In this section, we analyze the correlation between the measured and estimated value of the resin filling density obtained in the experiment by applying the T method. From the analysis results, we will verify the effectiveness of the important factors that affect the resin filling characteristics by applying the MT method.

\subsubsection{Correlation Analysis by $T$ Method}

Table 8 shows the level allocation table of the item variables related to the acquisition of the measured / estimated values of the resin filling density. Table 9 shows the experimental design table of the item variables for the resin filling density which is the objective variable (output value) based on Table 8 . 
Mechanical Engineering: An International Journal (MEIJ) Vol. 08, No. 1/2/3/4, November 2021

Table 8. Item variable level allocation table.

\begin{tabular}{|c|c|c|c|c|c|c|c|c|c|}
\hline Irem name & $\begin{array}{l}\text { Gate } \\
\text { widah }\end{array}$ & $\begin{array}{c}\text { Mold } \\
\text { temperanure }\end{array}$ & $\begin{array}{c}\text { Resin } \\
\text { temperature }\end{array}$ & $\begin{array}{c}\text { Measurement } \\
\text { level }\end{array}$ & $\begin{array}{l}\text { Retertion } \\
\text { pressture }\end{array}$ & $\begin{array}{l}\text { Screw } \\
\text { speed }\end{array}$ & $\begin{array}{c}\text { Bush } \\
\text { temperature }\end{array}$ & $\begin{array}{l}\text { Mold } \\
\text { type }\end{array}$ & $\begin{array}{l}\text { Injection } \\
\text { pressure }\end{array}$ \\
\hline Item symbol & $A(m u x)$ & $B(C)$ & $\mathrm{C}(\mathrm{C})$ & $\mathrm{D}$ (mun) & $E(M p o)$ & $F(r p m)$ & $\mathrm{G}(\mathrm{C})$ & $\mathrm{H}(-)$ & l(Mpa) \\
\hline Level 1 & 0.5 & 165 & 96 & 103 & 35 & 490 & 165 & 1 & 4 \\
\hline Level 2 & 0.8 & 175 & 102 & 105 & 45 & 510 & 185 & 2 & 8 \\
\hline Level 3 & - & 185 & 108 & 107 & 55 & 530 & 205 & - & 12 \\
\hline
\end{tabular}

Table 9. Design of experiments.

\begin{tabular}{|c|c|c|c|c|c|c|c|c|c|c|}
\hline \multirow{3}{*}{\multicolumn{2}{|c|}{ Experiment Na }} & \multirow{2}{*}{\multicolumn{9}{|c|}{ liem variables }} \\
\hline & & & & & & & & & & \\
\hline & & $\mathrm{A}$ & B & $\mathrm{C}$ & D & $E$ & $\mathrm{~F}$ & $G$ & $\mathrm{H}$ & $\mathrm{I}$ \\
\hline \multirow{13}{*}{$\begin{array}{l}\text { Unit } \\
\text { Space }\end{array}$} & I & 0.5 & 165 & 96 & 103 & 35 & 490 & 165 & 1 & 4 \\
\hline & 2 & 0.5 & 165 & 96 & 103 & 35 & 490 & 165 & 2 & 4 \\
\hline & 3 & 0.5 & 165 & 96 & 103 & 35 & 490 & 165 & 1 & 8 \\
\hline & 4 & 0.5 & 165 & 96 & 103 & 35 & 490 & 165 & 2 & 8 \\
\hline & 5 & 0.5 & 165 & 96 & 103 & 35 & 490 & 165 & 1 & 12 \\
\hline & 6 & 0.5 & 165 & 96 & 103 & 35 & 490 & 165 & 2 & 12 \\
\hline & : & : & $:$ & : & : & $:$ & : & $:$ & : & : \\
\hline & : & : & : & : & : & ; & : & : & : & : \\
\hline & : & : & : & 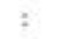 & : & : & : & : & : & : \\
\hline & : & : & : & : & : & : & : & : & : & : \\
\hline & : & ; & : & ; & : & : & : & ; & ; & : \\
\hline & 53 & 0.5 & 175 & 102 & 105 & 55 & 530 & 165 & 1 & 12 \\
\hline & 54 & 0.5 & 175 & 102 & 105 & 55 & 530 & 165 & 2 & 12 \\
\hline \multirow{15}{*}{$\begin{array}{l}\text { Sieval } \\
\text { Data }\end{array}$} & 55 & 0.5 & 175 & 108 & 107 & 35 & 490 & 185 & 1 & 4 \\
\hline & 56 & 0.5 & 175 & 108 & 107 & 35 & 490 & 185 & 2 & 4 \\
\hline & 57 & 0.5 & 175 & 108 & 107 & 35 & 490 & 185 & 1 & 8 \\
\hline & 58 & 0.5 & 175 & 108 & 107 & 35 & 490 & 185 & 2 & 8 \\
\hline & 59 & 0.5 & 175 & 108 & 107 & 35 & 490 & 185 & 1 & 12 \\
\hline & 60 & 0.5 & 175 & 108 & 107 & 35 & 490 & 185 & 2 & 12 \\
\hline & : & : & : & : & $:$ & : & $:$ & : & $:$ & : \\
\hline & : & : & : & ; & ; & ; & : & : & : & : \\
\hline & : & 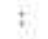 & : & : & t & ; & : & $z$ & : & t \\
\hline & : & : & : & : & : & : & : & : & $:$ & t \\
\hline & : & : & : & ; & : & : & : & : & : & : \\
\hline & 105 & 0.8 & 185 & 108 & 105 & 35 & 510 & 205 & 1 & 8 \\
\hline & 106 & 0.8 & 185 & 108 & 105 & 35 & 510 & 205 & 2 & 8 \\
\hline & 107 & 0.8 & 185 & 108 & 105 & 35 & $\$ 10$ & 205 & 1 & 12 \\
\hline & 108 & 0.8 & 185 & 108 & 105 & 35 & 510 & 205 & 2 & 12 \\
\hline
\end{tabular}

The item variables in the estimation of the output value are 9 items follows, A: Gate width (mm), B: Mold temperature $\left({ }^{\circ} \mathrm{C}\right), \mathrm{C}$ : Resin temperature $\left({ }^{\circ} \mathrm{C}\right)$, D: Measurement level $(\mathrm{mm})$, E: Retention pressure (MPa), F: Screw speed (rpm), G: Bush temperature $\left({ }^{\circ} \mathrm{C}\right)$, H: Mold type (-), I: Injection pressure (MPa). Experiment No.1 to 54 are set as unit space, and experiment No. 55 to 108 are set as signal data. Table 10 shows the actual measured value of the filling density and the calculation results of the estimated value by the T method, and Figure 7 shows the correlation distribution. Table 11 shows the calculation results of various coefficients that evaluate the correlation between the measured / estimated value of the filling density. From the calculation results of the correlation coefficient $(=0.913)$ and the coefficient of determination $(=0.834)$, a high correlation can be confirmed in the measured / estimated value of the filling density.

In the $\mathrm{T}$ method, it is possible to make a comprehensive estimate from the relationship between each item and the output value, and analyze the contribution to the estimated value for each item. The contribution of each item is the result of evaluation by the integrated estimate $\mathrm{SN}$ ratio (signalto-noise ratio: $\mathrm{db}$ ). The $\mathrm{SN}$ ratio is expressed by the ratio of the signal amount $\mathrm{S}$ and the noise $\mathrm{N}$, and is calculated by the signal (active component of the input energy) / noise (harmful component 
Mechanical Engineering: An International Journal (MEIJ) Vol. 08, No. 1/2/3/4, November 2021

that did not work effectively as an output). The degree of contribution of the item is evaluated by how bad (low) the SN ratio of the comprehensive estimation is. Therefore, we use a two-level orthogonal array based on statistical empirical rules. By using an orthogonal array, the reliability of the estimated value can be improved by comparing which item is important for the estimation accuracy and how much it is by the integrated estimate $\mathrm{SN}$ ratio [14].

Table 12 shows the calculation process of the integrated estimate $\mathrm{SN}$ ratio in the calculation of the estimated filling density. Table 13 shows the diagnostic results of the contribution to the estimated value for each item extracted when calculating the filling density. In the estimation of filling density, Figure 7shows the ratio of contributions calculated from the SN ratio difference between valid items and ineffective items, and Figure 8 shows the factor effect diagram.

Table 10. Analysis results of measured / Estimated value of the filling density.

\begin{tabular}{|c|c|c|}
\hline EXP. No & $\begin{array}{l}\text { measured vahe } \\
\text { density }\left(\mathrm{Kg} / \mathrm{m}^{3}\right)\end{array}$ & $\begin{array}{l}\text { estimated valixe } \\
\text { densiry }\left(\mathrm{kg} / \mathrm{m}^{3}\right)\end{array}$ \\
\hline 1 & 0.755 & 0.749 \\
\hline 2 & 0.771 & 0.768 \\
\hline 3 & 0.771 & 0.795 \\
\hline : & : & : \\
\hline : & : & : \\
\hline 11 & 0.786 & 0.801 \\
\hline 12 & 0.790 & 0.803 \\
\hline 13 & 0.761 & 0.776 \\
\hline : & : & : \\
\hline : & : & : \\
\hline : & : & : \\
\hline ; & : & ; \\
\hline 24 & 0.785 & 0.787 \\
\hline 25 & 0.781 & 0,778 \\
\hline : & : & : \\
\hline : & : & : \\
\hline : & : & : \\
\hline 85 & 0.745 & 0.755 \\
\hline : & : & : \\
\hline : & : & : \\
\hline : & : & ; \\
\hline : & : & : \\
\hline : & : & : \\
\hline 108 & 0.845 & 0.875 \\
\hline
\end{tabular}

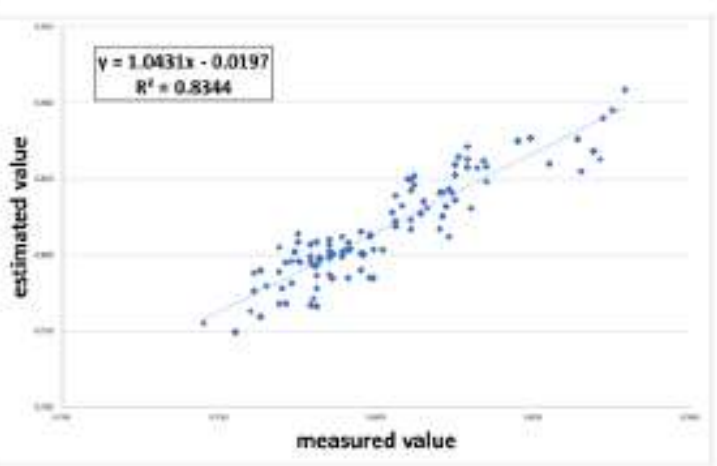

Figure 6. Correlation distribution of measured / estimated value of the filling density. 
Mechanical Engineering: An International Journal (MEIJ) Vol. 08, No. 1/2/3/4, November 2021

Table 11. Calculation results of correlation coefficient of measured / estimated value.

\begin{tabular}{|c|c|c|c|c|c|c|c|c|c|c|}
\hline ftem $\mathrm{Ne}$ & 1 & 2 & 3 & 4 & 5 & 6 & 7 & 8 & 9 & Demilly \\
\hline then symbils & $A$ & $B$ & c & D & E & F & G & H & 1 & $\left(\operatorname{kg} \mathrm{m}^{3}\right)$ \\
\hline Average value & 0.65 & 175 & 102 & 105 & 45 & 510 & 185 & 1.5 & $\overline{5}$ & 0.801 \\
\hline Stabdard deviation & 0.15 & 8.20 & 4.92 & 1.64 & 8.20 & 16.41 & 16.41 & 0.50 & 3.28 & 0.029 \\
\hline Regressicu coefficient & $3.28 \mathrm{E}-03$ & $-3.89 \mathrm{E}-13$ & $3.301-05$ & L.BOE-05 & $3.80 \mathrm{E}-13$ & $9.60 \mathrm{E}=08$ & $3.96 \mathrm{E}-06$ & 8.8.4E- -04 & $3.705-03$ & $\cdot$ \\
\hline Conrelation coefficient & - & - & - & - & - & $\cdot$ & + & $\cdot$ & - & 0.913 \\
\hline Coeftcient of determination & * & - & $=$ & - & - & $=$ & $=$ & $=$ & $=$ & 0.834 \\
\hline
\end{tabular}

Table 12. Calculation process of the integrated estimate SN ratio.

\begin{tabular}{|c|c|c|c|c|c|c|c|c|c|}
\hline ben No. & 1 & 2 & 3 & 4 & 5 & 6 & 7 & 8 & 9 \\
\hline Vem symbol & A & B & c & D & E & F & G & H & I \\
\hline Variation of proportional tean $S_{0}$ & 0.13 & 5.46 & 54.16 & 1.93 & 38.08 & 26.60 & 525.38 & 0.82 & 414.89 \\
\hline Error variatice $\mathrm{S}_{\text {, }}$ & 2.45 & 8061.21 & 2465.84 & 270.07 & 14578.58 & 27173.40 & 3174129 & 27.84 & 1483.77 \\
\hline Enor variance $V_{\text {, }}$ & 0.02 & 79.81 & 24.41 & 2.67 & 144.34 & 269.04 & 314.27 & 0.28 & 14.69 \\
\hline Proportional coefficiert $\beta$ & 1.18 & .7 .72 & 24.33 & 4.59 & -20.40 & 17.05 & 75.78 & 3.00 & 67.34 \\
\hline SN ratio ๆ & 46.22 & -10.18 & 13.31 & -3.05 & -8.05 & -9.85 & 734 & 21.76 & 297.73 \\
\hline liseprated estimate $\mathrm{SN}$ matio & & & & & $26,4(b)$ & & & & \\
\hline
\end{tabular}

Table 13. Contribution of items in calculation of estimated the filling density.

\begin{tabular}{ccccccccccc}
\hline hem No. & I & 2 & 3 & 4 & 5 & 6 & 7 & 8 & 9 \\
Vem syubal & A & B & C & D & E & F & 6 & I & I \\
\hline Level 1 & 22.40 & 21.83 & 21.96 & 20.58 & 20.89 & 20.79 & 21.07 & 21.53 & 25.60 \\
Level 2 & 20.10 & 20.66 & 20.54 & 21.92 & 21.61 & 21.71 & 21.42 & 20.97 & 16.90 \\
Coutriburical (db) & 2.30 & 1.17 & 1.42 & -1.34 & -0.72 & -0.91 & -0.35 & 0.56 & 8.70 \\
\hline
\end{tabular}
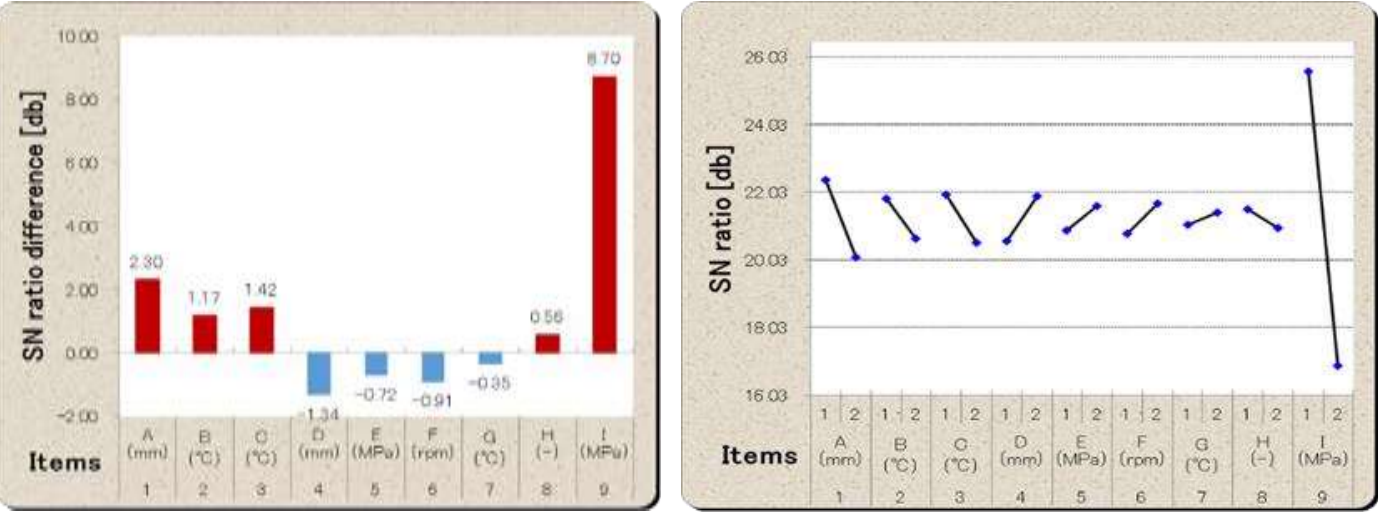

Figure 7. Contribution to the estimated

Figure 8. Factor effect diagram of items. filling density.

From the analysis results in Table 13 and Figures 7 and 8, the items that have a strong influence on the estimation of packing density are A: Gate width $(\mathrm{mm}), \mathrm{B}$ : Mold temperature $\left({ }^{\circ} \mathrm{C}, \mathrm{C}\right.$ : Resin temperature $\left({ }^{\circ} \mathrm{C}\right.$, and $\mathrm{H}$ : Mold type (-), I: Injection pressure (MPa). In particular, I: Injection pressure (MPa) accounts for $50 \%$ of the total contribution, so it can be inferred that it is an important item to consider in order to obtain a stable filling density.

\subsubsection{Effectiveness Analysis of Important Factors by MT Method}

Based on the results of the correlation analysis between the measured value and the estimated value of the resin filling density by the $\mathrm{T}$ method in the previous section, in this section, we clarify the effectiveness of important factors that affect the resin filling characteristics by applying the MT 
Mechanical Engineering: An International Journal (MEIJ) Vol. 08, No. 1/2/3/4, November 2021

method. Table 14 shows the calculation results of the standard deviation and correlation matrix in the unit space of experiment No.1 to 54 of the item variables ( 9 items) related to the acquisition of the resin filling density. Table 15 and Figure 9 show the MD calculation results based on the unit space information in Table 14. For the number of unit data is 54 , normal data is 54 , gray data is 0 , and abnormal data is 0 . From this calculation result, it can be judged that the level value of the item variable set to obtain the filling density is appropriate as the unit space (normal region). The basis for this judgment is that the MD threshold value is set to 4 based on statistical empirical rules in the quality engineering $(\mathrm{MD}$ average value $=0.89<4)[15]$.

Table 14. Calculation results of item variable standard deviation and correlation matrix.

\begin{tabular}{ccccccccccc}
\hline Irem No. & 1 & 2 & 3 & 4 & 5 & 6 & 7 & 8 & 9 \\
\hline 1 & 1.00 & -0.16 & -0.03 & 0.13 & 0.03 & -0.27 & 0.14 & 0.00 & 0.00 \\
2 & -0.16 & 1.00 & -0.40 & -0.21 & 0.40 & 0.00 & 0.18 & 0.00 & 0.00 \\
3 & -0.03 & -0.40 & 1.00 & 0.34 & 0.08 & 0.35 & -0.13 & 0.00 & 0.00 \\
4 & 0.13 & -0.21 & 0.34 & 1.00 & 0.81 & 0.18 & 0.02 & 0.00 & 0.00 \\
5 & 0.03 & 0.40 & 0.08 & 0.81 & 1.00 & 0.17 & 0.13 & 0.00 & 0.00 \\
6 & -0.27 & 0.00 & 0.35 & 0.18 & 0.17 & 1.00 & 0.31 & 0.00 & 0.00 \\
7 & 0.14 & 0.18 & -0.13 & 0.02 & 0.13 & 0.31 & 1.00 & 0.00 & 0.00 \\
8 & 0.00 & 0.00 & 0.00 & 0.00 & 0.00 & 0.00 & 0.00 & 1.00 & 0.00 \\
9 & 0.00 & 0.00 & 0.00 & 0.00 & 0.00 & 0.00 & 0.00 & 0.00 & 1.00 \\
\hline Average valute & 0.63 & 168.33 & 100.67 & 104.78 & 47.22 & 510.00 & 187.22 & 1.50 & 8.00 \\
Standard deviation & 0.15 & 4.71 & 4.71 & 1.47 & 7.86 & 16.33 & 17.50 & 0.50 & 3.27 \\
\hline
\end{tabular}

Table 15. Calculation results of unit space MD.

\begin{tabular}{|c|c|c|c|}
\hline No. & MD & MD & Frequency \\
\hline 1 & 0.94 & $<0.5$ & 6 \\
\hline 2 & 0.94 & $<1$ & 32 \\
\hline 3 & 0.77 & $<1.5$ & 16 \\
\hline 4 & 0.77 & $<2$ & 0 \\
\hline 5 & 0.94 & $<2.5$ & 0 \\
\hline 6 & 0.94 & $<3$ & 0 \\
\hline 7 & 0.47 & $<3.5$ & 0 \\
\hline 8 & 0.47 & $<4$ & 0 \\
\hline 9 & 0.31 & $<4.5$ & 0 \\
\hline 10 & 0.31 & $<5$ & 0 \\
\hline 11 & 0.47 & $<5.5$ & 0 \\
\hline 12 & 0.47 & $<6$ & 0 \\
\hline 13 & 0.99 & & \\
\hline 14 & 0.99 & & \\
\hline 15 & 0.83 & MD & verage \\
\hline 16 & 0.83 & 0.8 & $<4.0$ \\
\hline 17 & 0.99 & Non & al data \\
\hline 18 & 0.99 & & 54 \\
\hline ; & ; & Gr: & data \\
\hline ; & ; & & 0 \\
\hline ; & : & Abno & nal data \\
\hline ; & : & & 0 \\
\hline 52 & 0.97 & & \\
\hline 53 & 1.14 & & \\
\hline 54 & 1.14 & & \\
\hline
\end{tabular}

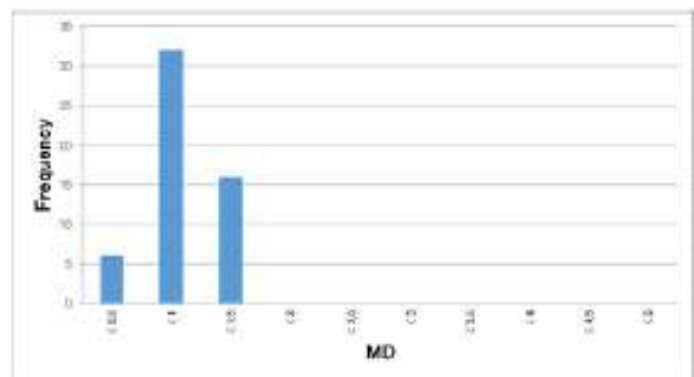

Figure 9. Unit space MD.

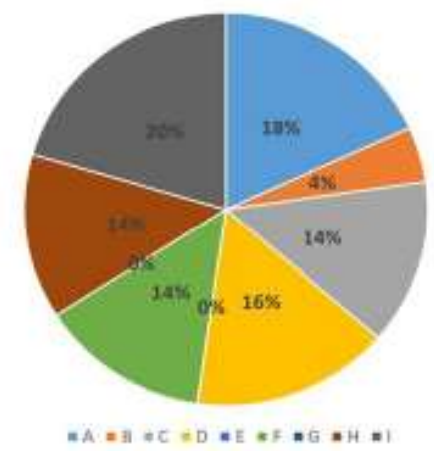

Figure 10. Effectiveness ratio of item variable.

Table 16. Calculation results of effectiveness ratio of item variable that affect resin filling characteristics. 
Mechanical Engineering: An International Journal (MEIJ) Vol. 08, No. 1/2/3/4, November 2021

\begin{tabular}{ccccccccccc}
\hline $\begin{array}{c}\text { Item No. } \\
\text { Item symbol }\end{array}$ & $\mathrm{A}$ & $\mathrm{A}$ & $\mathrm{B}$ & $\mathrm{3}$ & $\mathrm{C}$ & 5 & 6 & 7 & 8 & 9 \\
\hline $\begin{array}{c}\text { Effectiveness } \\
\text { ratio }(\%)\end{array}$ & $\mathbf{1 8}$ & 4 & 14 & 16 & 0 & 14 & 0 & 14 & $\mathbf{2 0}$ \\
\hline
\end{tabular}

Tables 16 and Figure 10 show the analysis results regarding the effectiveness of the item variables (9 items) that affect the resin filling characteristics from the MD calculation results based on the unit space information. From the analysis results regarding effectiveness, as in "Section 3.3.1 Correlation analysis results by the T method", item No. 9: Injection pressure (MPa) and No. 1: Gate width $(\mathrm{mm})$ are required to obtain a stable filling density. It can be judged that the item has a high effectiveness ratio (No. $9=20 \%$, No. $1=18 \%$ ) to be considered.

\section{Analysis of Resin Filling Characteristics by Robust Parameter Design}

In this chapter, we will clarify the level value of the optimum processing conditions that affect the uniformity of the resin filling density for the purpose of stabilizing the resin strength in the injection molding process. As an analysis method, we focus on the input / output relationship of resin molten energy and apply the functional evaluation method "Robust Parameter Design".

\subsection{Overview of Robust Parameter Design}

Robust Parameter Design (hereinafter referred to as RPD) is a technical methodology for improving quality systematized by its founder, Dr. Genichi Taguchi, for half a century. This is a method of reducing variations in the characteristics and functions of products and systems by designing control factors so that they are robust against noise factors such as usage environment conditions. RPD is a development philosophy that focuses on improving the reliability of products and systems. The purpose of improving reliability is to avoid being affected by factors that may adversely affect the reliability of the product.

As shown in Figure 11, the RPD approach requires four factors (signal factor, response factor, noise factor, and control factor) to be considered in the design process. The basic idea of RPD is to attenuate the effects of noise factors by finding effective control and noise factor interactions in the design. This is an economical and effective way to reduce variability simply by changing the level of control factors.

Robustness is a concept used in a wide range of fields such as computer programming, statistics, economics, biology, and information engineering, in addition to design and manufacturing. Robustness means ensuring "robust stability" in the performance of systems and products and improving reliability. In the RPD experiment, the noise factor intentionally causes variation in the combination of system parameters selected as the control factor, and the robustness is improved by optimizing the level of the strong control factor that can counter the variation. 


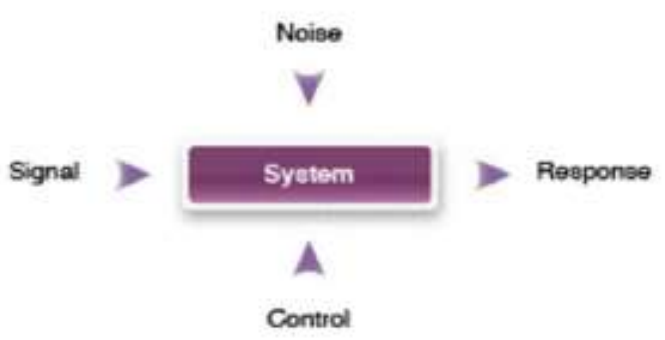

Figure 11. Conceptual diagram of RPD.

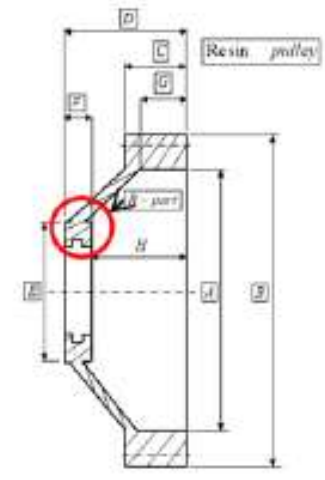

Figure 12. Pulley sectional view.

\subsection{Functional Evaluation Method and Ideal Function Setting}

The ideal function of many system technologies is that the output changes linearly with respect to the input. The total output characteristic value (total work) of the system must be proportional to energy or work. Especially in the injection molding process, there are melting energy required to obtain resin strength and dimensional accuracy, and loss energy that affects productivity. In the RPD, a "Functional evaluation method" that defines the functionality based on energy conversion and quickly evaluates its stability is important. In this research, we focus on the fact that the ideal function that represents the input-output relationship has a linear relationship with energy conversion. Figure 12 shows a cross-sectional view of the molded resin pulley component. The quality issue is that cracks occur in the $\mathrm{R}$ part indicated by the red circle due to insufficient mechanical strength and stress concentration. In this example, regarding the optimization of resin strength, the relational expression between the allowable stress of the resin material and the material density is newly defined as follows based on material mechanics considerations.

Allowable stress: $\sigma$

$$
\sigma=\frac{M}{Z}=K \cdot \rho
$$

$M$ : Moment of force $\quad$ : Section modulus $\quad K$ : Proportional factor $\quad \rho$ : Resin filling density

The physical quantity in Eq. (29) is regarded as constant for the dimension and shape [L] and the processing time $[\mathrm{T}]$, and is replaced with a unit of dimension. Since the moment of force $M=$ $\left[M L^{2} T^{-2}\right]$ and the section modulus $Z=\left[L^{3}\right]$,

It can be defined as $\sigma=\frac{\left[M L^{2} T^{-2}\right]}{\left[L^{3}\right]}=\left[L^{2} T^{-2}\right]\left[M L^{-3}\right]=K \cdot \rho$.

The allowable stress, which is an index of resin strength, is determined by the section modulus and the moment of force. Therefore, if the dimension and shape of the material and the processing time are constant, as shown in Eq. (29), it is the linear proportional (linear equation) to the allowable stress $\sigma$ and the material density $\rho$ with a proportional constant K. It can be defined as a relationship. Based on this definition, it can be estimated that stabilizing the degree of variation in the resin filling density $\rho$ is highly effective in optimizing the resin strength. To optimize the resin strength, the ideal function shown in Figure 13 is set from the function of controlling the resin filling density in the mold (input/output relationship of melting energy related to resin filling characteristics) and the material mechanical definition. The main purpose of applying the "Functional evaluation method" is to extract parameter levels that make the fusion energy parameter and the stable function of the filling density closer to the ideal state and reduce variations 
and fluctuations. The difference from the ideal state can be considered as some kind of energy loss. In other words, the function of injection molding is consumed other than the intended output, and as a result, the stability of the filling density is affected. The effectiveness of the ideal function, in which the input is used as the parameter (control factor) of the molding processing conditions related to the melting energy during resin flow and the resin filling density as the output is the characteristic value is verified.

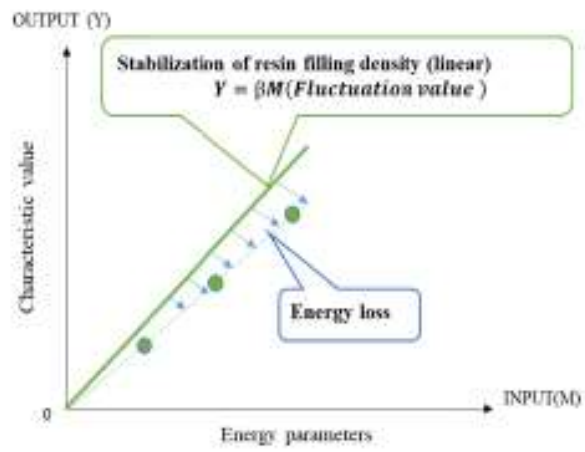

Table 17. Data form.

\begin{tabular}{|c|c|c|c|c|c|c|}
\hline & \multicolumn{5}{|c|}{ Input scgeal M } \\
\hline & & $\mathrm{MS}_{1}$ & $\mathbf{M S}_{2}$ & $\mathrm{As}_{3}$ & $\cdots$ & 34 \\
\hline \multirow{4}{*}{$\begin{array}{c}\text { Noise } \\
\text { Lactor } \\
\text { N }\end{array}$} & $\mathbf{s}_{1}$ & $y_{11}$ & $y_{D}$ & $y_{33}$ & $\cdots$ & $y_{\mathrm{h}}$ \\
\hline & $\mathbf{N}_{\mathrm{z}}$ & nit & $y_{n}$ & ys & $\cdots$ & $y_{t z}$ \\
\hline & & & & & & \\
\hline & $\mathrm{N}_{\mathrm{v}}$ & $\mathrm{Y}_{\mathrm{at}}$ & $y_{d t}$ & $y_{w}$ & $\ldots$ & $y_{15}$ \\
\hline
\end{tabular}

Figure 13. Relations of ideal function state.

\subsection{Energetic $\mathrm{SN}$ ratio}

The conventional SN ratio which is used in parameter design and represents the scale of variation may change depending on the size (range) of the input signal and the number of data, and the technician should keep this in mind when acquiring data. There is a problem of having to analyze. The idea of the SN ratio is to evaluate the variation and non-linearity from the ideal functional state $(\mathrm{y}=\beta \mathrm{M})$ by considering it as poor functional stability. The "Energetic SN ratio" adopted in this study is a new SN ratio announced in June 2008 by a research member of the Kansai Quality Engineering Society which is a certified regional study group of the Quality Engineering Society in japan [16]. Since all technologies involve the conversion and transfer of energy, an energy perspective is important in technological development and evaluation of their technical levels. Energetic SN ratio is a technical quality evaluation measure (measurement) based on how various energies are used. Technical quality means that more energy input to the system can be stably used for the purpose (output) forever. In the ideal functional state of injection molding, energy is decomposed into effective components $\left(\mathrm{S}_{\beta}\right)$ and harmful components $\left(\mathrm{S}_{\mathrm{N}}\right)$, and the energetic SN ratio is calculated by the ratio of these. In the calculation of the energetic SN ratio, it can be expressed in decibel value as 10 times the common logarithm like the conventional type SN ratio. The basic calculation formula of the energetic SN ratio $\eta_{E}$ is shown below. As shown in Table 17, it is assumed that the output $y_{i j}$ at the noise factor level $i(i=1,2, \cdots, n)$ and the signal factor level $j(j=1,2, \cdots, k)$ is obtained.

(a) Total variation component $S_{T}$

This is the sum of the squares of $n k$ pieces of data $y_{i j}$ and shows the variation from $y=0$

$$
S_{T}=\sum_{i=1}^{n} \sum_{j=1}^{k} y_{i j}{ }^{2}
$$

(b) Average slope size $\beta_{N 0}$ 
For some dynamic characteristics of the input signal, the slope of the noise factor $N_{i}$ level $\beta_{N i}$ is obtained by considering the effective component as the average slope.

$$
\beta_{N i}=\frac{\sum_{j=1}^{k} M_{j} y_{i j}}{\sum_{j=1}^{k} M_{j}^{2}}=\frac{L_{N i}}{r}
$$

Where:

$r$ : Effective divisor, $L_{N \mathrm{i}}$ : Linear format

$$
\begin{gathered}
r \equiv \sum_{j=1}^{k} M_{j}^{2} \\
L_{N i} \equiv \sum_{j=1}^{k} M_{j} y_{j}
\end{gathered}
$$

The sum of squares of the signal which is the denominator of $\beta$ in Eq. (31) is called the effective divisor $r$, and the sum of product of the numerator signal and output is called the linear form $L_{N i}$. From the slope $\beta_{N i}$ for each noise factor level, the average slope $\beta_{N 0}$ is given by the following equation

$$
\beta_{N 0}=\frac{\sum_{i=1}^{n} \beta_{N i}}{n}
$$

(c) Average slope fluctuation (active ingredient) $S_{\beta}$

$$
S_{\beta}=n \sum_{j=1}^{k}\left(\beta_{N 0} M_{j}\right)^{2}=n \beta_{N 0}{ }^{2} \sum_{j=1}^{k}\left(M_{j}\right)^{2}=n r \beta_{N 0}{ }^{2}
$$

The variation of the average slope is expressed as the sum of squares of the size $y=\beta_{N 0} M$.

(d) Harmful component $S_{N}$

The harmful component represents the variation of the difference between each data and the proportional equation of the average slope, and is obtained by subtracting the effective component from the total variation component.

$$
S_{N}=\sum_{i=1}^{n} \sum_{j=1}^{k}\left(y_{i j}-\beta_{N 0} M_{j}\right)^{2}=S_{T}-S_{\beta}
$$

(e) Energetic SN ratio $\eta E$

$$
\eta_{E}=10 \log \left(\frac{S_{\beta}}{S_{T}-S_{\beta}}\right)=10 \log \left(\frac{S_{\beta}}{S_{N}}\right)[\mathrm{db}]
$$

\subsection{Level Table and Determination of Various Factors}

In this section, the optimization of the processing conditions is verified by "dynamic characteristics evaluation" with the objective function of stabilizing the fusion energy parameter and the filling density in injection molding. The dynamic characteristic is a characteristic that examines the output by changing the input, and is a method of evaluating the condition that minimizes the two- 
Mechanical Engineering: An International Journal (MEIJ) Vol. 08, No. 1/2/3/4, November 2021

dimensional variation of the input and the output in the combination of various factors. In this section, the optimization of the processing conditions is verified by "dynamic characteristics evaluation" with the objective function of stabilizing the fusion energy parameter and the filling density in injection molding. The dynamic characteristic is a characteristic that examines the output by changing the input, and is a method of evaluating the condition that minimizes the twodimensional variation of the input and the output in the combination of various factors.

Table 18. Control factors.

\begin{tabular}{|c|c|c|c|c|}
\hline Symbol & Control factor & Level 1 & Level 2 & Level 3 \\
\hline A & Gate width (mm) & 0.5 & 0.8 & - \\
\hline B & Mold temperature $\left({ }^{\circ} \mathrm{C}\right)$ & 165 & 175 & 185 \\
\hline C & Resin temperature $\left({ }^{\circ} \mathrm{C}\right)$ & 96 & 102 & 108 \\
\hline D & Measurement level (mm) & 103 & 105 & 107 \\
\hline E & Retention pressure (Mpa) & 35 & 45 & 55 \\
\hline F & Screw speed (rpm) & 490 & 510 & 530 \\
\hline G & Bush temperature $\left({ }^{\circ} \mathrm{C}\right)$ & 165 & 185 & 205 \\
\hline H & Virtual factor & el & e2 & e3 \\
\hline
\end{tabular}

Table 19. Noise factors.

\begin{tabular}{lcc}
\hline Noise factor & N1 & N2 \\
\hline Mold type & No.1Die & No.2Die \\
\hline
\end{tabular}

Table 20. Signal factors.

\begin{tabular}{cccc|}
\hline Signal factor & M1 & M2 & M3 \\
\hline $\begin{array}{c}\text { Injection pressure } \\
\text { (Mpa) }\end{array}$ & 4.0 & 8.0 & 12.0 \\
\hline
\end{tabular}

\subsection{Analysis of Factorial Effects}

Figure 14 shows the SN ratio and sensitivity for each control factor in a factorial effect diagram. The vertical axes in the upper and lower figures represent the SN ratio, respectively, and the horizontal axes represent the factor level. The significance of this diagram is to extract factors that have a large SN ratio that spreads vertically and have a small effect on output sensitivity, and it can be judged that their level is highly significant in stabilizing the resin filling characteristics. In the dynamic characteristic evaluation, it is desirable that the value of the SN ratio is linearly large, and the optimal conditions are determined based on a comprehensive evaluation comparing the SN ratio and sensitivity factor effect diagrams.

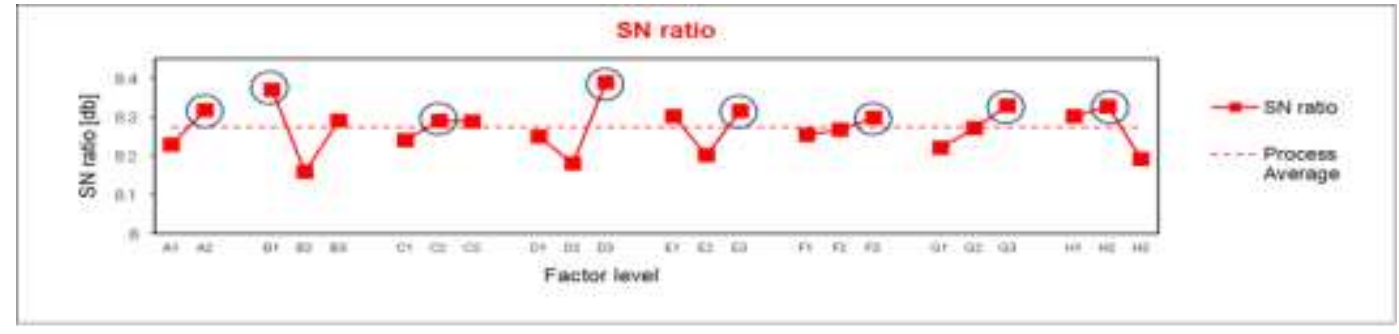

Figure 14. Factor effect diagram of the $\mathrm{SN}$ ratio.

\subsection{Evaluation of Reproducibility by Confirmation Experiment}

The purpose of the confirmation experiment is to confirm whether the output is stable even when the time, place, and environment change compared to the orthogonal table experiment. Table 21 shows the reproducibility evaluation results in the confirmation experiment. In the RPD, if the reproducibility of gain is within the range of $70 \%$ to $130 \%$, or the gain difference is within $\pm 3 \mathrm{db}$, it can be judged that there is reproducibility. In this experimental results, the reproducibility of the gain is $93 \%$ and the gain difference is $0.03 \mathrm{db}$. Furthermore, the stability improvement rate of the filling density against the BM condition is $20 \%$ and the energy loss is reduced by $36 \%$, indicating that the extracted optimal conditions are properly selected and the set ideal functional state is approached. Figure 15 is a graph comparing the input and output variations and the linear relationship between the optimal condition and the BM condition in the verification experiment. It 
Mechanical Engineering: An International Journal (MEIJ) Vol. 08, No. 1/2/3/4, November 2021

shows the change in output (filling density) with respect to input (injection pressure), and it is clear that the optimal condition has a stable linear proportional relationship with less variation than the $\mathrm{BM}$ condition.

Table 21. Reproducibility of confirmation experiment.

\begin{tabular}{|c|c|c|c|c|c|c|}
\hline & \multicolumn{3}{|c|}{ SN tafa [ate] } & \multicolumn{3}{|c|}{ Santinty [dt] } \\
\hline & Estamated & Cenfrumied & Rejustuctiany & Evematel & Conifrated & Roprodusibity \\
\hline BM zondtion & 8.26 & 7,85 & 9596 & -21.51 & -22.12 & 10396 \\
\hline Optimat cosafisim & 8.72 & 821 & 964 & $-21,00$ & -21.48 & 10296. \\
\hline Ginin & 0.38 & 0.36 & 234 & $65 t$ & 0.63 & $124 \%$ \\
\hline 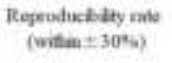 & Nonts & 9396 & $\leq 130 \%$ & $7056 \leq$ & 12425 & 51360 \\
\hline 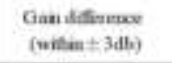 & $\underline{0.03}$ & $s=1 \mathrm{Alh}$ & & -0.12 & $5=3$ d & \\
\hline todpuest & \multicolumn{6}{|c|}{ Reproducith } \\
\hline Euersy bas & $\underline{x \leqslant 6}$ & 14.55 & (Thiss) & Reduction & & \\
\hline Demidy stabizy & 2006 & 1.24 & (Tuos) & Inproveruant & & \\
\hline
\end{tabular}

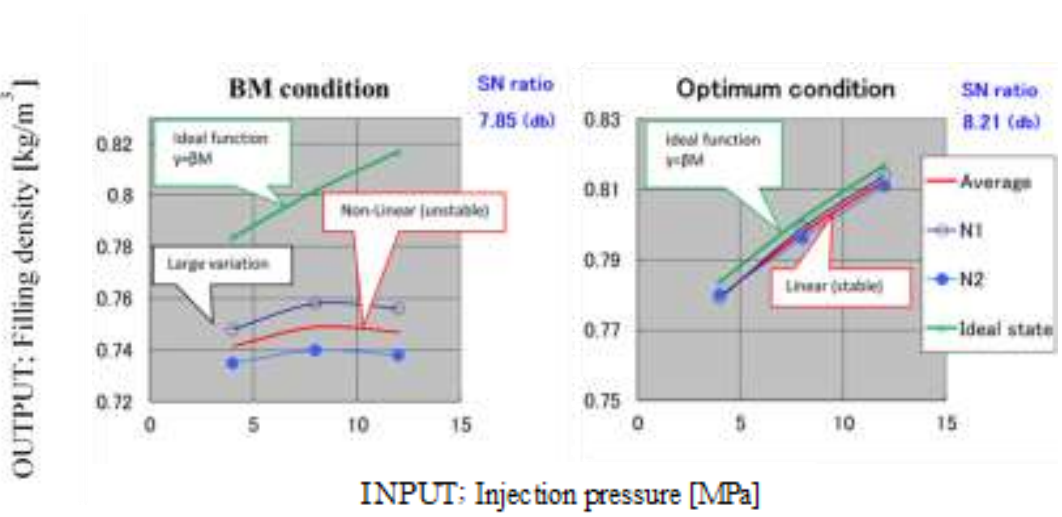

Figure 15. Input / Output linearity verification.

\section{CONCLUSION}

In this study, we focused on the function of controlling the resin filling density in the mold (input/output relationship of melting energy related to resin flow) in optimizing resin strength. From the new definition of resin strength based on material mechanical considerations, we applied a functional evaluation method that has the ideal function of stabilizing the resin filling density. It was clarified that the uniform resin filling density in the mold, which is a management function, is extremely important for stabilizing the resin strength. As a result of research, we achieved $50 \%$ reduction in in-process defect rate due to abolition of 100\% inspection and defective molding of resin pulleys (cracking/cracking of thin part) by improving process capability of resin filling density which is the current productivity index. Furthermore, it was verified that the application of the functional evaluation method, which has the ideal function of stabilizing the resin filling density, brings great knowledge in the optimization of the injection molding process. It has been clarified that the shape change due to the shrinkage rate of the resin in the mold is determined by the dimensional accuracy of the mold and the molded product, and is always in a linear proportional relationship.

As a future research topics, based on the results of this research, a new ideal function will be set for the relationship between the melt energy associated with the resin flow and the resin shrinkage rate in the mold. For the analysis of the strength of resin parts, we plan to apply the multivariate analysis method and RPD to further optimize the strength and dimensional accuracy of resin parts. 


\section{REFERENCES}

[1] Uesono H, et al (2015): History of Development of Injection Molding Machine Technologies and Future Perspectives, Japan Steel Works Technical Report (66), 23-33, ISSN:0369-562X.

[2] Natsume S and Kitayama S (2015): Multi-objective optimization in plastic injection molding with injection and packing time, Transactions of the JSME (in Japanese), Vol.81, No.830, DOI: 10.1299/transjsme.15-00028.

[3] Naganuma T and Hashimoto K (2019): Anomaly detection of the injection molding clamping unit, Transactions of the JSME (in Japanese), Vol.85, No.871, 2019, DOI: 10.1299/transjsme.1800258.

[4] Sawada R (2019): Robust Design of Complex System- Quality Engineering and Model Based Development-, Journal of Quality Engineering, Vol. 27, No. 6 p. 14-18, doi.org/10.18890/qes.27.6_14.

[5] Sakurai M, et al (2007): "Evaluation of uniform filling property of injection molded products by MT system", Lecture summary at Nihon University College of Industrial Science, pp.9-12.

[6] Maeda S (2017): Unusual Tiger-Striped Flow Mark Patterns Appeared in Injection Molding of Polypropylene/Talc Compounds, Journal of the Sociaty of Rheology, Japan, Vol.45, No.5, 269275, DOI: 10.1678/rheology.45.269.

[7] Takahashi K (2005): Optimization of thermoplastic equipment in injection molding machines, Journal of Quality Engineering, Vol.13, No.2, pp.53-59.

[8] Tsuneda S and Shimizu H (2011): Research on production process design method for injection molding-from parameter design of thermoplastic equipment to analysis by MT system-, Journal of Quality Engineering, Vol.19, No.1, pp.44-51.

[9] Tsuneda S (2007): Optimization of material drop port shape in injection molding machines, Journal of Quality Engineering, Vol.15, No.5, pp.174-180.

[10] Wakui Y and Wakui S (2014): Understanding Multivariate Analysis, Gijutsu-Hyoronsha, pp.190200, ISBN-10: 4774146390.

[11] Tatebayashi K, Teshima S and Hasegawa Y (2012): "Introduction MT System", Union of Japanese Scientists and Engineers, pp.133-174, ISBN-10: 4817192844.

[12] Suzuki M (2012): Introduction to MT System Analysis Method, Nikkan Kogyo Shimbun , 7-101. ISBN 10: 4526068918.

[13] Suzuki M (2018): Proposed Spectral Centroid Signal Monitoring System Using MahalanobisTaguchi Method, Journal of Quality Engineering, Vol.26, No.6, pp.16-22, doi.org/10.18890/qes.26.6_16.

[14] Oguro R, et al (2019): Customer number forecasting by using T-method in quality engineering, Summary of National Research Presentation Conference 201910 (0), 9-10, NAID: 130007771514, DOI: 10.11497 / jasmin.201910.0_9.

[15] Gomi N, at al (2017): Study of Signature Recognition System Based on MT System, Journal of Quality Engineering, Vol. 25, No. 6 p. 33-40, doi.org/10.18890/qes.25.6_33.

[16] Tsuruta H (2016): Energetic SN ratio, Union of Japanese Scientists and Engineers, ISBN: 978-481719594-4. 